\title{
Editorial: Twenty years of Bone Marrow Transplantation in Pakistan- Lessons Learnt and Future Vision
}

The year 2015 marked the completion of twenty years of Bone Marrow Transplant (BMT) programme in Pakistan. In September 1995, first procedure was done on a 19 year old boy suffering from acute myeloid leukaemia. He succumbed to intestinal TB few months later. During the first decade, transplant activity was very slow, only 350 BMT were carried out by only 03 centres. 02 BMT centres were working in Karachi while only 01 in Rawalpindi. The main indications of transplant were aplastic anaemia, $\beta$-thalassaemia major and haematological malignancies. Only HLA (Human Leucocyte Antigen) matched procedures were performed. The reported outcome was promising, treatment related mortality remained 10-20\%, while 05 -year survival was reported to be 78,72 and $49 \%$ in aplastic anaemia, $\beta$-thalassaemia major and acute leukaemia/ chronic myeloid leukaemia respectively [1].

Pakistan has an estimated population of 196 million (2014 est.) with a growth rate of 1.49\% and a birth rate of 23.19/1000; life expectancy: 67.05. Pakistan's GDP/PPP as of 2013 was $\$ 574.1$ billion; per capita, 100. Human development index (as of 2006) was very low i.e. 0.55 [2].

With this population growth rate, an estimated 10,000 patients need bone marrow transplantation annually in the country. Only 150 BMT procedures are being performed annually by all BMT centres (4 active centres) together. This means, current BMT activity is only catering $1.5 \%$ of the total requirement. This gross disparity is a serious pitfall in healthcare system. We need at least 50 BMT centres in the country, each with a capacity of performing 200 procedures annually. Currently 09 centres are registered with Human Organ Transplant Authority (HOTA), while only 04 are actively doing BMT.

By the end of second decade, 1500 BMT procedures have been carried out (National data presented in 3rd International Stem Cell Transplantation Conference in November 2016 at AFIP, Rawalpindi, Pakistan). Indications of BMT remained the same as published by Shamsi T, et al. in 2008. Outcome has been reported to be improved (personal communication with BMT centres and data presented in the conference in AFIP in 2016). During second decade, bone marrow donor shortage issue became the major hurdle for patients. Pakistan doesn't have unrelated bone marrow donor registry neither local cord blood banks. To overcome donor shortage, NIBD and BMT Karachi, initiated haploidentical donor programme in 2013 with encouraging results.

There are distinct differences between our programme and the transplant programmes worldwide. Firstly, allogeneic transplantation is done more frequently than the autologous transplantation. The ratio is almost 9:1. Both CIBMTR and EBMT data suggests that autologous transplantation is more commonly performed procedure; the ratio is 3:2 [3,4]. Second, most procedures are done in children as compared to adults. This is because of the indications of BMT i.e. aplastic anaemia, $\beta$ thalassaemia major and fanconi's anaemia [1]. This is in sharp contrast to global data, where acute myeloid leukaemia, myelodysplastic syndrome, and acute lymphoblastic leukaemia remain the most common indications. Third, CMV seropositivity among donor-recipients pair in Pakistan is around 99\%, as compared to 60\% globally [1]. Fourth, gram-negative infections remain high [1,5]. Tuberculosis, malaria, intestinal parasites are endemic here. BMT centres have to take actions to screen, treat pre-emptively or give prophylaxis against these organisms. Fifth, incidence of acute and chronic GvHD (Graft versus host disease) is rather low as compared to the western data; its reasons are largely unknown $[4,5]$.

So far transplant programme has been running in non-governmental sector. There is a meagre financial support from government for selected group of patients [6]. There is no system of third party payment to support bone marrow transplant patients. Many newer drugs used for BMT are not registered /available in Pakistan [7]. We need allocation of funds in federal and provincial health budgets for establishing BMT centres. We also need developmental budgets to establish more BMT 
centres to carry out the required number of BMT annually. Main focus should be to develop BMT training programmes for doctors, nurses, clinical pharmacists and other allied health care professionals to meet the future demand of human resource in this area.

To conclude, Pakistan has completed two decades of BMT programme. We are far behind to catch-up the unmet need of our population. We have to strive to expand the infrastructure, train and retain human resource and get financial support to sustain the BMT programme.

\section{REFERENCES}

[1] Shamsi T, Hashmi K, Adil S, et al. The stem cell transplant program in Pakistan- the first decade. Bone Marrow transplant. $2008 ; 42$ suppl 1: $114-117$. DOI:10.1038/bmt.2008. 137

[2] Infoplease.com [internet].2017.Maps, History, Geography, Government, Culture, Facts, Guide and Travel/Holidays/Cities; page1. Available from http://www.infoplease.com/country/pakistan.html?pageno=1

[3] EBMT Annual Report 2014.[internet]. Available at https://www.ebmt.org/contents/resources/library/annual report/documents/EBMT_Annual report_2014.pdf

[4] Pasquini M, Zhu X. Current uses and outcomes of hematopoietic stem cell transplantation: CIBMTR Summary Slides, 2015. Available at: http://www.cibmtr.org

[5] Ansari SH, Nasim S, Ahmed A, et al. Febrile neutropenia in paediatric peripheral blood Stem cell transplantation,in-vitro sensitivity data and clinical response to empirical antibiotic therapy. J. Coll. Phys. Surg. Pak., 2006; 16:704-708.

[6] Shamsi T, Irfan M, Farzana T, Ansari S, Panjwani V, Taj M, et al. Survival and graft versus host disease in first 100 patients undergoing allogeneic peripheral blood stem cell transplantation: a single center experience. J. Pak. Med. Assoc., 2005; 55:469-475.

[7] Hashmi K, Khan B, Ahmed P, et al. Graft versus host disease in allogeneic stem cell transplantation-3 1/2 years experience. J. Pak. Med. Asssoc. 2005; 55:423-427.

doi.org/10.21089/njhs.22.0047

Editor-In- Chief

Tahir Shamsi

National Institute of Blood Diseases and Bone Marrow Transplantation, Karachi, Pakistan. 